\title{
Genetic polymorphisms of ERCC1 and their effects on the efficacy of cisplatin-based chemotherapy in advanced esophageal carcinoma
}

\author{
YONG WANG ${ }^{1-4}$, JIAN CHEN $^{4}, \mathrm{XIAOQIU} \mathrm{LI}^{4}, \mathrm{YIFU} \mathrm{HE}^{4}, \mathrm{BING} \mathrm{HU}^{4}, \mathrm{CHUSHU}_{\mathrm{JI}}^{4}$ and JIANMING XU ${ }^{1-3}$ \\ Departments of ${ }^{1}$ Gastroenterology and ${ }^{2}$ Presbyatrics, The First Affiliated Hospital, Anhui Medical University, \\ Hefei 230022; ${ }^{3}$ The Key Laboratory of Gastroenterology of Anhui Province, Hefei 230022; ${ }^{4}$ Department of \\ Oncology, The Affiliated Provincial Hospital, Anhui Medical University, Hefei 230001, P.R. China
}

Received October 21, 2010; Accepted December 23, 2010

DOI: $10.3892 / o r .2011 .1170$

\begin{abstract}
The aim of this study was to investigate the relationship between the ERCC1-C8092A, ERCC1-C19007T and GSTP1-A105G genetic polymorphisms and the curative effect of cisplatin-based chemotherapy in advanced esophageal carcinoma. A total of 256 pathologically confirmed advanced esophageal carcinoma patients were given regimens of cisplatin and 5-fluorouracil. Clinical evaluations were obtained from 241 patients who completed the therapy. The remission rate of patients with ERCC1-C8092A, A/C or A/A was higher compared to that of patients with $\mathrm{C} / \mathrm{C}$ (51.75 vs. $29.59 \%, \mathrm{P}<0.01)$. Progression-free survival of patients with ERCC1-C8092A, A/C or A/A was longer compared to that of patients with $\mathrm{C} / \mathrm{C}$ (7.5 months vs. 4.5 months, $\mathrm{P}<0.0001)$. The C19007T and GSTP1-A105G genetic polymorphisms were not positively correlated with remission rates and progressionfree survival of patients. In conclusion, the ERCC1-C8092A genetic polymorphism may be correlated with the efficacy of cisplatin-based chemotherapy in cases of advanced esophageal carcinoma. Further studies with a larger sample size are needed for tailored chemotherapy treatment of advanced esophageal carcinoma.
\end{abstract}

\section{Introduction}

Esophageal carcinoma is one of the most common gastrointestinal malignancies. Epidemiological study data show that

Correspondence to: Dr Jianming Xu, Department of Gastroenterology/Presbyatrics, The Key Laboratory of Gastroenterology, The First Affiliated Hospital, Anhui Medical University, Hefei 230022, P.R. China

E-mail: xjm1017@yahoo.com.cn

Dr Bing Hu, Department of Oncology, The Affiliated Provincial Hospital, Anhui Medical University, Hefei 230001, P.R. China E-mail: hubing3756@hotmail.com

Key words: advanced esophageal carcinoma, genetic polymorphisms, cisplatin, fluorouracil the incidence rates of esophageal carcinoma differ regionally. There is a high incidence rate of esophageal carcinoma in China. In fact, China has the highest incidence and morbidity rates in the world (1). Currently, the exact reason for the differences in rate of incidence among the populations is still unknown. It may be associated with the living habits and genetic susceptibility of individuals within a given population. In addition, there are obvious differences in the histology of esophageal carcinoma between cases in China when compared to those in Western countries. Squamous cell carcinoma is distributed over $90 \%$ of China, but adenocarcinoma is more common in Western countries. This difference may lead to different levels of treatment efficiency. Surgery and radiotherapy are the main treatments for early esophageal carcinoma, whereas intravenous systemic chemotherapy is one of the palliative remedies for patients in the advanced stages at the time of diagnosis or for those who experience a recurrence or metastasis and can not tolerate surgery due to factors such as old age or systemic disease. Although there is no standard first-line chemotherapy, the regiment of cisplatin/ fluorouracil is widely used clinically because of its low price and high efficiency (2).

Unfortunately, many patients receive only slight benefit of treatment with these toxic agents; therefore, the pursuit to identify patients who would really benefit from specific regimens is important. Identification of these patients, classifying them, and the use of optimal therapy for each subgroup would be a breakthrough in esophageal carcinoma management. The excision repair cross-complementation group 1 (ERCC1), was found for the first time, by transfecting the human genome DNA into Chinese hamster ovary (CHO) cells that were UV-sensitive mutants. It plays a role in the nucleotide excision repair pathway, which recognizes and removes cisplatininduced DNA adducts (3). It has been speculated that single nucleotide polymorphisms (SNPs) in DNA repair genes may change gene expression and activity and hence, influence the effectiveness of cancer treatment and survival of patients (4).

Previous research on lung and colon cancers shows that sensitivity to platinum anticancer drugs is associated with the genetic polymorphisms of ERCC1-C8092A (5), 
Table I. Primer sequences for detection of genetic polymorphisms.

Gene Primer sequence

ERCC1-C8092A

ERCC1-C19007T

GSTP1-A105G
Forward: 5'-ACAGTGCCCCAAGAGGAGAT-3'

Reverse: 5'-AGTCTCTGGGGAGGGATTCT-3'

Forward: 5'-GAGAGGGCTGAGCTGGAGACAG-3'

Reverse: 5'-CCAGCACATAGTCGGGAATTACGTC-3'

Forward: 5'-ACCCCAGGGCTCTATGGGAA-3'

Reverse: 5'-TGAGGGCACAAGAAGCCCCT-3'
ERCC1-C19007T (6), and glutathione-S-transferase P1 (GSTP1) GSTP1-A105G (7). The polymorphisms of these 3 alleles were shown to be associated with the chemotherapy effect in tumors such as non-small cell lung cancer (5), gastric adenocarcinoma (8), and epithelial ovarian cancer (6) in populations of Japan (9), Korea (6), France (10), and America (11). However, there are no previous studies on the association of these allele polymorphisms with sensitivity to platinum-based chemotherapy in advanced stages of esophageal cancer in the Chinese Han population. The aim of our study to investigate whether or not the polymorphisms of ERCC1 and GSTP1 genes are associated with chemotherapy efficiency. In order to accomplish this, we carried out a study on cisplatin-based chemotherapy in 241 patients. Fluorouracil with cisplatin was used in the treatment of patients of Chinese Han ethnicity with advanced esophageal cancer and the polymorphisms of the 3 alleles were detected. Data from our study was combined with other clinical and pathological features and then used to explore the relationship between these factors and patient's response rate (RR) and overall progression-free survival (PFS) after chemotherapy. We aim to provide some selection criteria for individualized treatment of chemotherapy for advanced esophageal cancer.

\section{Materials and methods}

Study subjects. Initially, 256 patients were randomly selected from the patients treated at the First Affiliated Hospital of Anhui Medical University, Anhui Provincial Hospital, and the Cancer Hospital of Anhui Province from September 2006 to September 2009. The eligibility criteria were: i) patient was diagnosed with histologically confirmed advanced esophageal cancer; ii) patient was 18-70 years old, with ECOG (The Eastern Cooperative Oncology Group) performance status 0-2; and iii) patient had at least one evaluable metastasis. Blood samples were collected from patients before chemotherapy and DNA was extracted from nucleated cells. Informed consent was obtained from each patient and the scientific protocol was approved by the local ethics committee.

Fifteen patients were excluded for the following reasons: Genotype could not be determined $(n=3)$, the level of treatment efficacy could not be assessed $(n=3)$, contact with the patient was lost $(n=5)$, and owing to intolerable toxicity $(n=4)$. Therefore, finally, 241 patients were enrolled in the study.
Chemotherapy regimen. All patients received 5-fluorouracil and cisplatin chemotherapy, one course every 3 weeks. The regimen included administration of $75 \mathrm{mg} / \mathrm{m}^{2}$ cisplatin over the course of 3-5 days (day 1-3 or 5), whereas $750 \mathrm{mg} /\left(\mathrm{m}^{2} \cdot \mathrm{d}\right.$ ) fluorouracil was administered continuously for 5 days.

Response evaluation. Response evaluation referred to RECIST 1.1 (Response Evaluation Criteria in Solid Tumors, 2009) (12) and was divided into complete response (CR), partial response (PR), stable disease (SD), and progressive disease (PD). After 2 cycles, we evaluated curative effect. If the disease was progressing, we evaluated the effect ahead of time. RR was defined as CR + PR, and PFS was defined as the time between the beginning of chemotherapy and disease progress.

Detection of the genetic polymorphisms of ERCC1 and GSTP1. The blood samples from patients were collected the morning before the first chemotherapy and DNA was extracted from nucleated cells via phenol extraction assay, and then amplified by PCR assay. PCR primers were provided by Shanghai Sangon Biological Engineering Technology \& Services Co., Ltd. (Table I). The Reaction System included: 10X buffer $(15 \mathrm{mM}$ $\left.\mathrm{Mg}^{2+}\right) 2.5 \mu \mathrm{l}, 2.5 \mathrm{mM}$ dNTPs $2 \mu \mathrm{l}, 10 \mu \mathrm{M}$ upsteam primer $0.5 \mu \mathrm{l}, 10 \mu \mathrm{M}$ downsteam primer $0.5 \mu \mathrm{l}, 5 \mathrm{U} / \mu \mathrm{l}$ Taq $0.2 \mu \mathrm{l}$, and sample (genome DNA) $50 \mathrm{ng}$. Sterile distilled water was added to the mixed system until it reached a total volume of $5 \mu \mathrm{l}$. Reaction conditions were: $95^{\circ} \mathrm{C}$ for $5 \mathrm{~min}, 94^{\circ} \mathrm{C}$ for $15 \mathrm{sec}$, $60^{\circ} \mathrm{C}, 25 \mathrm{sec}$, and $72^{\circ} \mathrm{C}$ for $30 \mathrm{sec}$. A total of 40 cycles were run at $72^{\circ} \mathrm{C}$, for $10 \mathrm{~min}$, and then saved at $4^{\circ} \mathrm{C}$. The PCR products were sequenced by Shanghai Sangon Biological Engineering Technology \& Services Co., Ltd., and the sequencing results were analyzed for genetic polymorphisms.

Statistical analysis. The Hardy-Weinberg equation for the equilibrium of allele distributions was used to statistically evaluate our data along with the $\chi^{2}$ test or Fisher's exact test. These tests were used to examine differences between gene polymorphism and RR. For multivariate analysis, we used a logistic regression model to test the difference between gene polymorphism and RR. The median PFS was generated using the Kaplan-Meier method. The relationship between genotype and PFS was detected by using a log-rank or Cox regression model for univariate or multivariate analysis, respectively. The level of significance was set to $\mathrm{P}<0.05$ and all analysis was conducted using the SPSS 16.0 statistical package (SPSS Inc., Chicago, IL, USA). 
Table II. Results of genetic equilibrium tests.

\begin{tabular}{lrcc}
\hline Genotype & $\mathrm{N}$ & $\chi^{2}$ & P-value \\
\hline ERCC1-C8092A & & & \\
A/A & 37 & 0.07737 & 0.78088 \\
A/C & 111 & & \\
C/C & 93 & & \\
ERCC1-C19007T & & & \\
C/C & 130 & 3.30501 & 0.06907 \\
C/T & 81 & & \\
T/T & 30 & & \\
GSTP1-A105G & & & \\
A/A & 182 & 2.72222 & \\
A/G & 49 & & \\
G/G & 10 & & \\
\hline
\end{tabular}

\section{Results}

Subject characteristics. A total of 241 patients were enrolled in this study. The patients were 171 males (70.95\%), 70 females (29.05\%), 78 patients with age $<60$ (32.37\%), and 163 patients with an age $\geq 60(67.63 \%)$. ECOG performance status was found to be 0 (16.18\%), $1(54.36 \%)$, and $2(29.46 \%)$ in 39,131 , and 71 patients, respectively. The pathological types encountered were squamous cell carcinoma, except one small cell type. The number of individuals with squamous cell carcinoma of well-to-moderate differentiation was 174 (72.50\%), whereas the number of individuals with squamous cell carcinoma of low differentiation was 66 (27.50\%).

Genetic equilibrium test. The genotype distributions of the 3 sites were determined to be in Hardy-Weinberg equilibrium with a P-value $>0.05$. Thus, this sample could represent a Mendelian population with a genetic equilibrium (Table II).

Genetic polymorphisms of ERCC1 and GSTP1. The DNA extracted from patient blood samples was then subjected to a PCR assay. The products of this PCR amplification were then sequenced and the resulting sequences were analyzed for genetic polymorphisms. The sequencing results are shown in Figs. 1, 2 and 3.

Genotype and response rate. After 241 patients with advanced esophageal carcinoma were treated with 2 cycles of cisplatin and fluorouracil chemotherapy. The total RR was $42.74 \%$; $4(1.66 \%)$ patients were in complete remission, $99(41.08 \%)$ were partly responsive, and $100(41.49 \%)$ remained stable. In the remaining $38(15.77 \%)$ patients, the disease was still progressing.

The relationship between the response rate, genotype, and other factors affecting the overall therapeutic effect of the chemotherapeutical treatment was examined using the $\chi^{2}$ test. The results showed that only the polymorphism of ERCC1-C8092A was statistically significantly associated with remission rate (Table III). The remission rate in patients
A

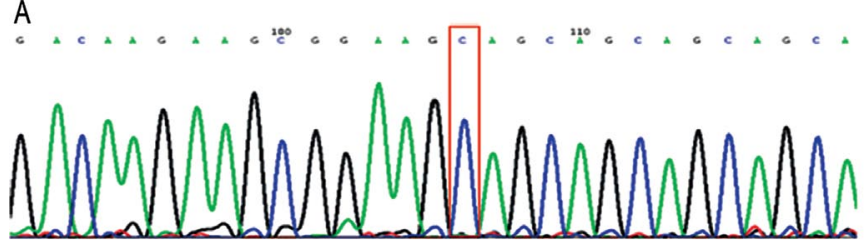

B

B

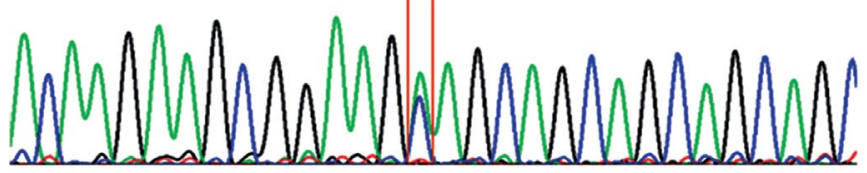

C

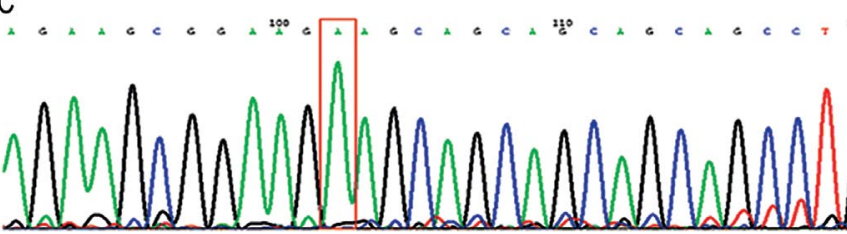

Figure 1. The DNA sequencing results for ERCC1-C8092A genetic polymorphisms analysis in genotype (A) $\mathrm{C} / \mathrm{C}$, (B) A/C, (C) A/A. (A) DNA seaquence of patients with ERCC1-C8092A as C/C. (B) DNA seaquence of patients with ERCC1-C8092A as A/C. (C) DNA seaquence of patients with ERCC1-C8092A as A/A.

A

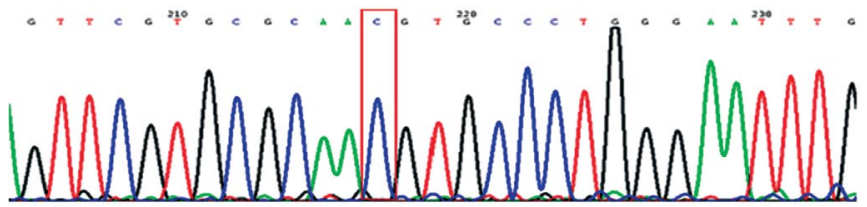

B

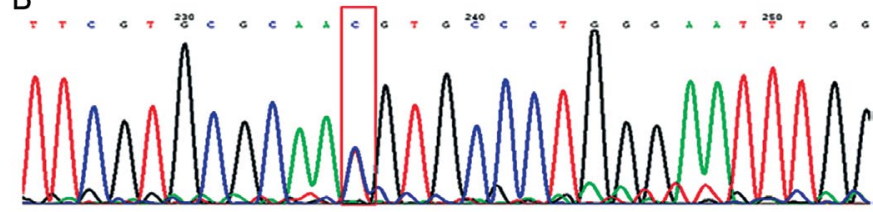

C

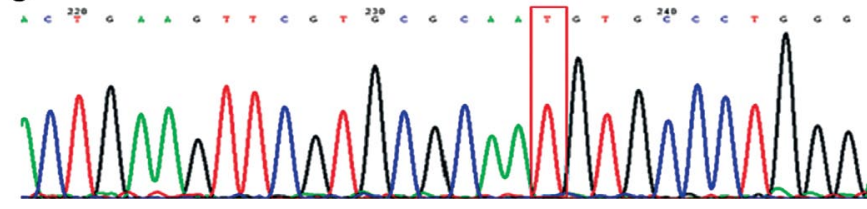

Figure 2. The DNA sequencing results for ERCC1-C19007T genetic polymorphisms analysis in genotype (A) C/C, (B) C/T, (C) T/T. (A) DNA seaquence of patients with ERCC1-C19007T as C/C. (B) DNA seaquence of patients with ERCC1-C19007T as C/T. (C) DNA seaquence of patients with ERCC1-C19007T as T/T.

with genotype $\mathrm{A} / \mathrm{C}$ or $\mathrm{A} / \mathrm{A}$ was higher than that with genotype $\mathrm{C} / \mathrm{C}$ (51.75 vs. $29.59 \%, \mathrm{P}<0.01)$.

The relationship between the response rate, genotype, and other factors affecting the overall therapeutic effect of the chemotherapy was further analyzed using a logistic regression model. These results indicated that only the polymorphism of ERCC1-C8092A was correlated with the remission rate too, in an amount that could be considered to be statistically 


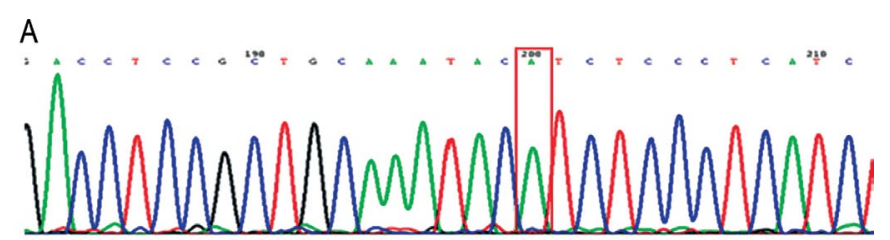

B

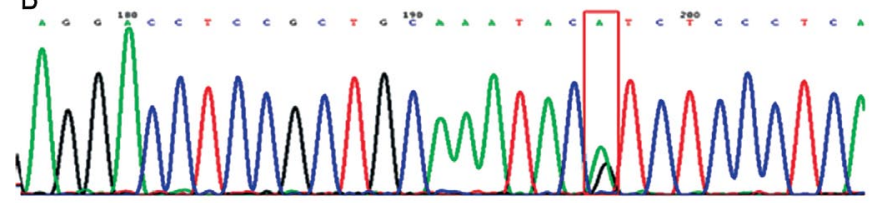

C

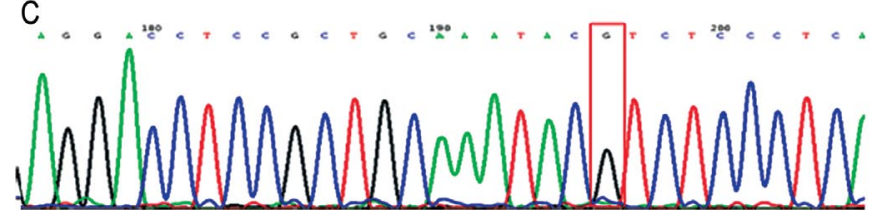

Figure 3. The DNA sequencing results for GSTP1-A105G genetic polymorphisms analysis in genotype (A) A/A, (B) A/G, (C) G/G. (A) DNA seaquence of patients with GSTP1-A105G as A/A. (B) DNA seaquence of patients with GSTP1-A105G as A/G. (C) DNA seaquence of patients with GSTP1-A105G as $\mathrm{G} / \mathrm{G}$.

significant. The chemosensitivity in patients with type $\mathrm{A} / \mathrm{C}$ or $\mathrm{A} / \mathrm{A}$ was 2.624 times higher than those with type $\mathrm{C} / \mathrm{C}(95 \%$ CI: $1.105-6.231)$.

Genotype and progression free survival. From September 2006 to September 2009, patients who were examined as part of our study were followed up with for 9-15 months until disease progression could be noted. The median PFS time was 5.9 months, ranging from 1.4 to 10.6 months. Log-rank analysis results showed that the association between polymorphism and the differentiation of ERCC1-C8092A for PFS time was statistically significant (Fig. 4). The PFS of ERCC1-C8092A site of patients with genotype A/C or A/A was longer than that of patients with type $\mathrm{C} / \mathrm{C}$ (7.5 months vs. 4.5 months, $\mathrm{P}<0.0001)$. Disease progression in the patients of poorly differentiated tumor cells happened earlier than it did in patients with well-differentiated tumor cells (3.0 months vs. 6.1 months, $\mathrm{P}<0.0001)$.

The relationship between the PFS, genotype, and other factors that may affect the overall therapeutic effect of this type of chemotherapy were further analyzed using a Cox regression model. The results showed that disease progression risk in patients with genotype $\mathrm{C} / \mathrm{C}$ was 1.976 times higher than in those with genotype A/A or A/C (95\% CI: 1.187-3.026) Disease progression risk in patients with poorly differentiated tumor cells (including one small cell type) was 2.371 times higher than that in patients with well-differentiated tumor cells (95\% CI: 1.311-3.882).

\section{Discussion}

Platinum drugs kill tumor cells mainly by binding with the nucleophilic DNA to form platinum-DNA complexes. The platinum-DNA adducts damage DNA due to DNA cross-linking between chains or chain cross-linking. This

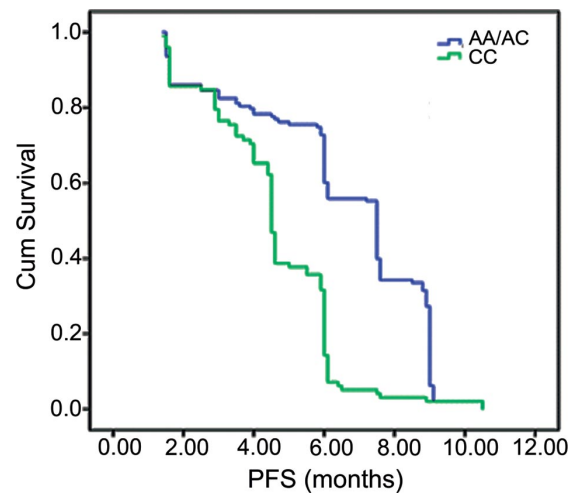

Figure 4. The relationship between genetic polymorphism of ERCC1C8092A and PFS.

process eventually leads to cell death. ERCC1 is a kind of endonuclease that can excise injured DNA fragments. Drug resistance to platinum agents can emerge if the injured DNA is repaired in time. As a result, the expression of ERCC1 is associated with drug resistance to platinum agents $(5,13)$.

ERCC1 is a component of the nucleotide excision repair pathway, a major repair mechanism of DNA damage induced by platin compounds reacting with DNA and forming interstrand and intrastrand cross links. The balance of DNA damage to DNA repair dictates tumor cell death or survival after cisplatin therapy (14). It plays a key role in the process of nucleotide excision repair (nucleotide excision repair, NER) and is the leading gene in NER pathway (15). In this study we found that most of the platinum-DNA adducts produced by chemotherapy were recognized and repaired by the nucleotide excision repair system (16). The study of Vogel et al (17) showed that ERCC1-XPF was the most important factor involved in nucleotide excision repair. The genetic polymorphism of ERCC1 determined the strength of its DNA repair capacity by affecting the mRNA stability and protein expression (18). As a result, the genetic polymorphism of ERCC1 was deduced to affect the chemotherapy sensitivity of platinum drugs.

At present, ERCC1 polymorphism studies are focused on single nucleotide polymorphisms of alleles C8092A and C19007T. Bralbury et al (19) reported a total of 150 patients with esophageal carcinoma received platinum-based drugs chemotherapy, radiotherapy, and surgery. The clinical evaluations demonstrated that a short-term RR and PFS in patients with ERCC1-C8092A genotype A/A or A/C was better than that in the patients with genotype $\mathrm{C} / \mathrm{C}$, which were consistent with our findings. They also found that overall survival (OS) and PFS in patients with genotype $\mathrm{A} / \mathrm{C}$ or $\mathrm{A} / \mathrm{A}$ were longer than that in those with genotype $\mathrm{C} / \mathrm{C}(\mathrm{P}=0.03$ and $\mathrm{P}=0.04)$. Patients with genotype $\mathrm{A} / \mathrm{C}$ or $\mathrm{A} / \mathrm{A}$ may have been more sensitive to platinum-based drugs. The ERCC1-C8092A polymorphism is located in the 3'-untranslated region of ERCC1, and the single-nucleotide change $\mathrm{C}$ to A that occurs at 8092 may affect ERCC1 mRNA stability (20). Therefore, the polymorphism of ERCC1-C8092A sites may be used to predict curative effect of cisplatin in the patients with advanced esophageal carcinoma. Although the polymorphism of ERCC1-C19007T site was reported to be associated with 
Table III. The results of $\chi^{2}$ test analysis on the relationship between genotypes, response rates, and other factors affecting therapeutic effect.

\begin{tabular}{|c|c|c|c|c|c|c|}
\hline & \multicolumn{2}{|c|}{ Response } & \multicolumn{2}{|c|}{ No response } & \multirow[b]{2}{*}{$\mathrm{RR}(\%)$} & \multirow[b]{2}{*}{$\chi^{2}$} \\
\hline & $\mathrm{CR}$ & PR & SD & PD & & \\
\hline \multicolumn{7}{|l|}{ Gender } \\
\hline Male & 3 & 71 & 64 & 33 & 43.27 & \multirow[t]{2}{*}{0.069} \\
\hline Female & 1 & 28 & 36 & 5 & 41.43 & \\
\hline \multicolumn{7}{|l|}{ Age (years) } \\
\hline$<60$ & 3 & 28 & 30 & 17 & 39.74 & \multirow[t]{2}{*}{0.423} \\
\hline$\geq 60$ & 1 & 71 & 70 & 21 & 44.17 & \\
\hline \multicolumn{7}{|l|}{ ECOG PS } \\
\hline 0 & 2 & 16 & 17 & 4 & 46.15 & \multirow[t]{3}{*}{0.213} \\
\hline 1 & 1 & 54 & 56 & 20 & 41.98 & \\
\hline 2 & 1 & 29 & 27 & 14 & 42.25 & \\
\hline \multicolumn{7}{|l|}{ Differentiation } \\
\hline Poorly differentiated ${ }^{a}$ & 2 & 21 & 12 & 32 & 34.33 & \multirow[t]{2}{*}{2.682} \\
\hline Well-differentiated & 2 & 78 & 88 & 6 & 45.98 & \\
\hline \multicolumn{7}{|l|}{ ERCC1-C8092A } \\
\hline $\mathrm{C} / \mathrm{C}$ & 2 & 27 & 56 & 13 & 29.59 & \multirow[t]{2}{*}{11.664} \\
\hline $\mathrm{A} / \mathrm{A}$ or $\mathrm{A} / \mathrm{C}$ & 2 & 72 & 44 & 25 & 51.75 & \\
\hline \multicolumn{7}{|l|}{ ERCC1-C19007T } \\
\hline $\mathrm{C} / \mathrm{C}$ & 2 & 54 & 56 & 18 & 43.08 & \multirow[t]{2}{*}{0.013} \\
\hline $\mathrm{C} / \mathrm{T}$ or $\mathrm{T} / \mathrm{T}$ & 2 & 45 & 44 & 20 & 42.34 & \\
\hline \multicolumn{7}{|l|}{ GSTP1-A105G } \\
\hline $\mathrm{A} / \mathrm{A}$ & 3 & 81 & 68 & 30 & 46.15 & \multirow[t]{2}{*}{3.543} \\
\hline $\mathrm{A} / \mathrm{G}$ or $\mathrm{G} / \mathrm{G}$ & 1 & 18 & 32 & 8 & 32.20 & \\
\hline
\end{tabular}

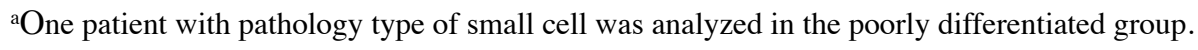

curative effect of cisplatin, the results were inconsistent. By investigating the patients with advanced non-small cell lung cancer who were treated with cisplatin combination chemotherapy, Ryu et al (21) found that OS in the patients with genotype $\mathrm{C} / \mathrm{C}$ was better than that in patients with genotype $\mathrm{C} / \mathrm{T}$ or $\mathrm{T} / \mathrm{T}(\mathrm{P}=0.0058)$. The patients with genotype $\mathrm{C} / \mathrm{C}$ were more sensitive to platinum drugs. In previous studies of ovarian cancer, Kang et al (6) found that the possibility of drug resistance in patients with genotype $\mathrm{T} / \mathrm{T}$ or $\mathrm{C} / \mathrm{T}$ was smaller than that in patients with genotype $\mathrm{C} / \mathrm{C}$ after receiving platinum-based chemotherapy. In our study, the ERCC1-C19007T polymorphism was not significantly associated with RR or PFS. The inconsistent results may be because of different sources of tumor cells and variation in pathological type. Further studies are needed to confirm our results.

GST is a multi-functional drug-metabolizing enzyme, and GSTP1, which belongs to GST isozyme family, is widely found in human tumor tissues. The enzyme catalyzes glutathione combining it with many cytotoxic compounds, including chemotherapy drugs. This promotes drug excretion and reduces the efficacy of anti-cancer drugs. Platinum drugs can be cleared in this way until the appearance of drug resis- tance. Therefore, it was shown that expression of GSTP1 was associated with drug resistance to platinum (22). Similarly, the genetic polymorphisms of GSTP1 may influence its expression in vivo. It was proved that the genetic polymorphism of GSTP1 had an effect on the overall curative effect of platinum drugs in gastric cancer (23), lung cancer (7), and colorectal cancer (24). These studies showed that curative effect of platinum drugs in patients with genotype $A / G$ or $\mathrm{G} / \mathrm{G}$ was better than that in patients with genotype A/A. However, we found that the genetic polymorphism of GSTP1 was not significantly correlated with the effects of chemotherapy in patients with advanced esophageal carcinoma. This was because the distribution of GSTP1 in esophageal squamous carcinoma cells was less than that in other tumors, and as a result, the detoxification effect of GSTP1 did not play a dominant role in the metabolism of cisplatin.

It has remained controversial whether a genetic polymorphism of ERCC1 was associated with chemotherapy of platinum in the past. Correlational studies have mainly focused on lung cancer (2), gastric cancer (22), colon cancer (25), and ovarian cancer (11). Our study showed that cisplatin treatment in patients with genotype $\mathrm{A} / \mathrm{A}$ or $\mathrm{A} / \mathrm{C}$ was more effective than that in patients with $\mathrm{C} / \mathrm{C}$ genotype in advanced 
esophageal squamous carcinoma in the Chinese Han population. The regimen that contains platinum should be avoided in treatments for patients with genotype $\mathrm{C} / \mathrm{C}$. This may reduce unnecessary side effects and economic costs to some extent. Our results may provide a molecular basis for the individualized systemic treatment of advanced esophageal carcinoma.

The sample enrolled in this study had a limited representative feature, and the respective expression levels of ERCC1 in patients' normal and tumor tissues were unclear. Whether the genotype of ERCC1 was induced by chemotherapy and radiotherapy, and its effect on OS is not clear. All these concerns make this topic worthy of further study.

\section{Acknowledgements}

We are grateful to all our patients for their participation, and the hospital staff for their cooperation. This study was supported by a grant from Natural Science Foundation of Anhui Province (No. 070413256).

\section{References}

1. Wei WQ, Yang J, Zhang SW, Chen WQ and Qiao YL: [Analysis of the esophageal cancer mortality in 2004-2005 and its trends during last 30 years in China]. Zhonghua Yu Fang Yi Xue Za Zhi 44: 398-402, 2010.

2. Llson DH: Esophageal cancer chemotherapy: recent advances. Gastrointest Cancer Res 2: 85-92, 2008.

3. Maeda J, Hirano T, Ogiwara A, et al: Proteomic analysis of stage I primary lung adenocarcinoma aimed at individualisation of postoperative therapy. Br J Cancer 98: 596-603, 2008.

4. Bernig T and Chanock SJ: Challenges of SNP genotyping and genetic variation: its future role in diagnosis and treatment of cancer. Expert Rev Mol Diagn 6: 319-331, 2006.

5. Yuan P, Miao XP, Zhang XM, et al: [Correlation of genetic polymorphisms in nucleotide excision repair system to sensitivity of advanced non-small cell lung cancer patients to platinum-based chemotherapy]. Ai Zheng 24: 1510-1513, 2005.

6. Kang S, Ju W and Kim JW: Association between excision repair cross-complementation group 1 polymorphism and clinical outcome of platinum-based chemotherapy in patients with epithelial ovarian cancer. Exp Mol Med 38: 320-324, 2006.

7. Sun N, Sun X, Chen B, Cheng H, Feng J, Cheng L and Lu Z: MRP2 and GSTP1 polymorphisms and chemotherapy response in advanced non-small cell lung cancer. Cancer Chemother Pharmacol 65: 437-446, 2009.

8. Fareed KR, Al-Attar A, Soomro IN, et al: Tumour regression and ERCC1 nuclear protein expression predict clinical outcome in patients with gastro-oesophageal cancer treated with neoadjuvant chemotherapy. Br J Cancer 102: 1600-1607, 2010.

9. Shibata Y, Baba E, Ariyama H, et al: Metastatic basaloidsquamous cell carcinoma of the esophagus treated by 5-fluorouracil and cisplatin. World J Gastroenterol 13: 3634-3637, 2007.

10. Malandrino P, Al Ghuzlan A, Castaing M, et al: Prognostic markers of survival after combined mitotane- and platinumbased chemotherapy in metastatic adrenocortical carcinoma. Endocr Relat Cancer 17: 797-807, 2010.
11. Krivak TC, Darcy KM, Tian C, et al: Relationship between ERCC1 polymorphisms, disease progression, and survival in the Gynecologic Oncology Group Phase III Trial of intraperitoneal versus intravenous cisplatin and paclitaxel for stage III epithelial ovarian cancer. J Clin Oncol 26: 3598-3606, 2008.

12. Eisenhauer EA, Therasse P, Bogaerts J, et al: New response evaluation criteria in solid tumours: revised RECIST guideline (version 1.1). Eur J Cancer 45: 228-247, 2009.

13. Fujii T, Toyooka S, Ichimura K, et al: ERCC1 protein expression predicts the response of cisplatin-based neoadjuvant chemotherapy in non-small cell lung cancer. Lung Cancer 59: 377-384, 2008.

14. Metzger R, Leichman CG, Danenberg KD, et al: ERCC mRNA levels complement thymidylate synthase mRNA levels in predicting response and survival for gastric cancer patients receiving combination cisplatin and fluorouracil chemotherapy. J Clin Oncol 16: 309-316, 1998.

15. Reed E, Dabholkar M, Thornton K, Thompson C, Yu JJ and Bostick-Bruton F: Evidence for in the appearance of mRNAs of nucleotide excision repair genes, in human ovarian cancer tissues. Oncol Rep 7: 1123-1128, 2000.

16. Wood RD: DNA repair in eukaryotes. Annu Rev Biochem 65: 135-167, 1996.

17. Vogel U, Dybdahl M, Frentz G and Nexo BA: DNA repair capacity: inconsistency between effect of over-expression of five NER genes and the correlation to mRNA levels in primary lymphocytes. Mutat Res 461: 197-210, 2000.

18. Chen P, Wiencke J, Aldape K, et al: Association of an ERCC1 polymorphism with adult-onset glioma. Cancer Epidemiol Biomarkers Prev 9: 843-847, 2000.

19. Bradbury PA, Marshall AL and Kulke AH: Prognostic significance of nuclear excision (NER) and base excision (BER) DNA repair gene polymorphisms in esophageal cancer. 2007 ASCO Annual Meeting Proceedings (Post-Meeting Edition). J Clin Oncol 25: 2511, 2007.

20. Park DJ, Zhang W, Stoehlmacher J, et al: ERCC1 gene polymorphism as a predictor for clinical outcome in advanced colorectal cancer patients treated with platinum-based chemotherapy. Clin Adv Hematol Oncol 1: 162-166, 2003.

21. Ryu JS, Hong YC, Han HS, et al: Association between polymorphisms of ERCC1 and XPD and survival in non-small cell lung cancer patients treated with cisplatin combination chemotherapy. Lung Cancer 44: 311-316, 2004.

22. Kwon HC, Roh MS, Oh SY, Kim SH, Kim MC, Kim JS and Kim HJ: Prognostic value of expression of ERCC1, thymidylate synthase, and glutathione S-transferase P1 for 5-fluorouracil/ oxaliplatin chemotherapy in advanced gastric cancer. Ann Oncol 18: 504-509, 2007.

23. Ruzzo A, Graziano F, Kawakami K, et al: Pharmacogenetic profiling and clinical outcome of patients with advanced gastric cancer treated with palliative chemotherapy. J Clin Oncol 24: 1883-1891, 2006

24. Stoehlmacher J, Park DJ, Zhang W, Groshen S, Tsao-Wei DD, $\mathrm{Yu} \mathrm{MC}$ and Lenz HJ: Association between glutathione S-transferase P1, T1, and M1 genetic polymorphism and survival of patients with metastatic colorectal cancer. J Natl Cancer Inst 94: 936-942, 2002.

25. Yang LY, Li L, Jiang H, Shen Y and Plunkett W: Expression of ERCC1 antisense RNA abrogates gemicitabine-mediated cytotoxic synergism with cisplatin in human colon tumor cells defective in mismatch repair but proficient in nucleotide excision repair. Clin Cancer Res 6: 773-781, 2000. 